\title{
Comparative effects of dietary wheat bran and its morphological components (aleurone and pericarp-seed coat) on volatile fatty acid concentrations in the rat
}

\author{
BY BING-QIN CHENG ${ }^{1}$, RODNEY P. TRIMBLE2, \\ RICHARD J. ILLMAN², BRUCE A. STONE ${ }^{1}$ \\ AND DAVID L. TOPPING ${ }^{2 *}$ \\ ${ }^{1}$ Department of Biochemistry, La Trobe University, Bundoora, Victoria 3083, Australia \\ ${ }^{2}$ CSIRO (Australia) Division of Human Nutrition, Glenthorne Laboratory, Majors Road, \\ O'Halloran Hill, South Australia 5158, Australia
}

(Received 18 March 1986 - Accepted 13 August 1986)

\begin{abstract}
1. Adult male rats were fed on diets containing $100 \mathrm{~g}$ dietary fibre $/ \mathrm{kg}$ either as $\alpha$-cellulose or wheat bran or the pericarp-seed coat or aleurone layers prepared from that bran by sequential milling and air elutriation and electrostatic separation.

2. After $10 \mathrm{~d}$, concentrations of total volatile fatty acids (VFA) in caecal fluid were significantly different between groups and fell in the order: aleurone $>$ wheat bran $>$ pericarp-seed coat $>$ cellulose. This ranking probably reflected the ease of fermentation of fibre polysaccharides by colonic bacteria which also resulted in a considerably higher faecal bacterial mass in the aleurone group.

3. Because of the differences in the volume of caecal digesta, the mass of caecal VFA was considerably the highest in the aleurone group, intermediate with wheat bran and equally low in the pericarp-seed coat and cellulose groups.

4. The diet based on aleurone gave a relatively higher proportion of propionate but with both pericarp-seed coat and wheat bran the contribution of butyrate was raised.

5. VFA concentrations in hepatic portal venous plasma were proportional to caecal concentrations with very high ( $>3 \mathrm{~mm}$ ) values being recorded in the aleurone group.

6. The findings are discussed in relation to the apparent susceptibility of the morphological components of wheat bran to fermentation by large bowel bacteria.
\end{abstract}

A number of cell wall polysaccharides and gums that are constituents of dietary plant fibre do not completely survive transit through the gastrointestinal tract of humans and other omnivores such as the rat and pig (for a brief review, see Topping \& Illman, 1986). In these species, the breakdown of such polysaccharides is effected through a bacterial fermentation, especially in the large bowel, which closely resembles that occurring in the rumen and with similar end-products, the volatile fatty acids (VFA) acetate, propionate and butyrate (Remesy et al. 1980; Argenzio \& Stevens, 1984). The degree of fermentation depends upon the polysaccharide component under consideration. Thus cellulose has been reported to be a relatively poor substrate, whereas non-cellulosic polysaccharides such as pectins and $(1 \rightarrow 3,1 \rightarrow 4)$ - $\beta$-glucans are extensively degraded. Lignin, which is a complex polyphenolic polymer that is a component of certain plant cell walls, passes through the gastrointestinal tract almost completely unaltered (Topping \& Illman, 1986).

Experiments with purified plant polysaccharides have shown that VFA concentrations in the caecal digesta and hepatic portal venous plasma of rats reflect their apparent digestibility. Thus, high concentrations were obtained with pectin and an acidic arabinogalactan (gum arabic) relative to cellulose (Illman et al. 1982; Storer et al. 1984). Similar findings have been obtained with cereal-bran preparations. For example, oat bran yielded high VFA levels whereas wheat bran did not (Illman et al. 1982; Storer et al. 1983). Of course, it must be borne in mind that these two bran fractions differ in the proportion of different morphological components of the parent grain.

\footnotetext{
* For reprints.
} 
In comparing effects of or responses to diets containing such milled cereal fractions, it is important to take into account the intrinsic qualitative and quantitative differences in cell wall polysaccharides in the various cell types and also the effects of milling conditions on the proportions of those cells in different grain species. In particular, it would be of help to understand the nutritional responses to brans if the effects of the various morphological components could be ascertained separately. Recently, a procedure has become available for obtaining from wheat bran the aleurone and pericarp-seed coat fragments with a low degree of cross-contamination. Both are obtained free of starchy endosperm (J. Minifie and B. A. Stone, patent pending). Here we compare the effects of dietary adaptation to wheat bran and these aleurone and pericarp-seed coat preparations on the concentrations of VFA and other metabolites in the rat. Purified cellulose was included in a reference diet as a fibre of low apparent digestibility.

\section{MATERIALS AND METHODS}

\section{Care of animals}

Twenty-four adult male rats of the Hooded Wistar strain were used. The animals, which weighed 190-205 g at the start of the experiment, were randomized into groups of six and each group was raised in separate stainless steel cages with wire mesh bottoms. The rats were kept in a room of controlled lighting (10.00-20.00 hours) and heating $\left(21 \pm 1^{\circ}\right)$ and with low background noise and were allowed free access to food and water.

\section{Preparation of diets}

There were four experimental diets based on cellulose (C), wheat bran (WB), wheat pericarp-seed coat (PC), wheat aleurone (AL). The $\alpha$-cellulose was obtained from the Sigma Chemical Co., St Louis, MO, USA. Wheat bran (racehorse bran) was commercially milled from Victorian soft wheat (90-100\% cv Egret, 1981-1982 season) by Water Wheel Flour Mills, Bridgewater, Victoria, Australia. This bran was used to formulate the WB diet and was the starting material for the preparation of aleurone and pericarp-seed coat. The latter were prepared by a sequence of impact milling, air elutriation and electrostatic separation. The parent wheat bran and isolated fractions were analysed for crude fibre (Association of Official Analytical Chemists, 1984) and dietary fibre (Asp et al. 1983) and their composition is shown in Table 1. The compositions of the four experimental diets are given in Table 2. Diets were formulated (Storer et al. 1983) to contain $(\mathrm{g} / \mathrm{kg}) 635$ digestible carbohydrate (of which $235 \mathrm{~g}$ was sucrose), 150 protein, 100 dietary fibre. Each fibre preparation was added to give the latter level while appropriate corrections were made in the addition of maize starch, casein and maize oil for the carbohydrate, protein and fat contents of the wheat brand, aleurone and pericarp-seed coat. Diets were mixed thoroughly, hand pelleted and kept at $0-4^{\circ}$ under $\mathrm{N}_{2}$.

\section{Feeding of rats, sampling and analytical procedures}

The animals were allowed free access to food and water for $10 \mathrm{~d}$. From Monday to Friday food consumption and faecal output were measured daily whereas for Saturday and Sunday measurements were averaged over $2 \mathrm{~d}$. Faecal samples were taken and frozen at $-20^{\circ}$ for analysis. After $10 \mathrm{~d}$ of dietary modification the animals were taken in random order from each group, lightly anaesthetized with diethyl ether and blood drawn from the hepatic portal vein $(2 \mathrm{ml})$ and systemic aorta $(8 \mathrm{ml})$. The blood was collected into ice-cold tubes for the determination of blood glucose and plasma VFA and, in arterial samples, plasma cholesterol and triacylglycerols (Illman et al. 1982; Storer et al. 1983). Whole caeca were excised, the contents extruded and weighed. The contents were diluted with water for 
Table 1. Analyses of wheat bran and of aleurone and pericarp-seed coat fragments $(\mathrm{g} / \mathrm{kg})$

\begin{tabular}{lccc}
\multicolumn{1}{c}{ Constituent } & Wheat bran & Aleurone & $\begin{array}{c}\text { Pericarp-seed } \\
\text { coat }\end{array}$ \\
\hline Moisture & 99 & 91 & 80 \\
Crude protein (nitrogen $\times 6 \cdot 25)$ & 156 & 234 & 86 \\
Fat (acid hydrolysis) & 49 & 64 & 27 \\
Available carbohydrate & 234 & 264 & 63 \\
Crude fibre & 109 & 41 & 185 \\
Dietary fibre & 453 & 324 & 673 \\
\hline
\end{tabular}

Table 2. Composition of the experimental diets $(\mathrm{g} / \mathrm{kg})$

\begin{tabular}{|c|c|c|c|c|}
\hline Component & Cellulose & Wheat bran & Aleurone & $\begin{array}{c}\text { Pericarp-seed } \\
\text { coat }\end{array}$ \\
\hline Sucrose & $491 \cdot 5$ & $491 \cdot 5$ & $491 \cdot 5$ & $491 \cdot 5$ \\
\hline Maize starch & $163 \cdot 4$ & $93 \cdot 6$ & $55 \cdot 5$ & $132 \cdot 0$ \\
\hline Casein & $153 \cdot 2$ & $118 \cdot 6$ & $80 \cdot 8$ & $140 \cdot 4$ \\
\hline Safflower oil & $61 \cdot 3$ & $45 \cdot 0$ & $32 \cdot 9$ & $56 \cdot 8$ \\
\hline Vitamin mixture & $3 \cdot 5$ & $3 \cdot 5$ & 3.5 & $3 \cdot 5$ \\
\hline Salt mixture & $24 \cdot 0$ & $24 \cdot 0$ & $24 \cdot 0$ & $24 \cdot 0$ \\
\hline Methionine & $3 \cdot 1$ & $3 \cdot 1$ & $3 \cdot 1$ & $3 \cdot 1$ \\
\hline Cellulose & $100 \cdot 0$ & - & - & - \\
\hline Wheat bran & - & $220 \cdot 7$ & - & - \\
\hline Aleurone & - & - & $308 \cdot 7$ & - \\
\hline Pericarp & - & - & - & $148 \cdot 7$ \\
\hline
\end{tabular}

determination of caecal pH and VFA (Storer et al. 1983). The content of bacteria in faeces was estimated by a modification of the methods of Stephen \& Cummings (1980) and was expressed as a percentage of faecal dry weight. The liver was excised, blotted dry and weighed and portions (of approximately $1 \mathrm{~g}$ each) used for the determination of glycogen and triacylglycerols (Topping et al. 1979).

\section{Statistical methods}

Unless otherwise indicated, values are shown as the mean with their standard errors for six observations per group. Statistical evaluation was by analysis of variance and a value of $P<0.05$ was taken as the criterion of significance.

RESULTS

Food intake, faecal output and body-weight gain

Food intake in each group remained constant over the $10 \mathrm{~d}$ experimental period and also did not differ significantly between diets, mean values: $19 \cdot 7,20 \cdot 7,21.7$ and $19.7 \mathrm{~g} / \mathrm{rat}$ per $\mathrm{d}$ for the $\mathrm{C}, \mathrm{WB}, \mathrm{PC}$ and $\mathrm{AL}$ groups respectively. In keeping with these rates of intake, faecal output was similar with all dietary treatments and averaged $3.6 \mathrm{~g} / \mathrm{rat}$ per $\mathrm{d}$ (all groups, combined).

Faecal bacterial mass was measured in all groups at the end of the experiment and averaged $11.1 \%$ of faecal dry weight in the C group and 12.6 and $7.3 \%$ in the WB and PC groups. The highest contribution was in the AL group where bacteria represented $42.5 \%$ of faecal dry matter. 
Table 3. Concentrations of total and individual volatile fatty acids (VFA) and the amount of total VFA in the caecal digesta of rats fed on diets containing wheat bran $(W B)$, aleurone $(A L)$, pericarp-seed coat $(P C)$ and cellulose $(C)$

(Mean values with their standard errors for six observations per group)

\begin{tabular}{|c|c|c|c|c|c|c|c|c|c|c|}
\hline \multirow[b]{3}{*}{ Diet } & \multicolumn{8}{|c|}{ Concentration of caecal VFA $(\mu \mathrm{mol} / \mathrm{ml}$ digesta) } & \multirow{2}{*}{\multicolumn{2}{|c|}{$\begin{array}{c}\text { Total VFA } \\
(\mu \mathrm{mol})\end{array}$}} \\
\hline & \multicolumn{2}{|c|}{ Acetate } & \multicolumn{2}{|c|}{ Propionate } & \multicolumn{2}{|c|}{ Butyrate } & \multicolumn{2}{|c|}{ Total } & & \\
\hline & Mean & SE & Mean & SE & Mean & $\mathrm{SE}$ & Mean & SE & Mean & SE \\
\hline WB & $144^{a}$ & 4 & $33^{a}$ & 2 & $54^{a}$ & 6 & $235^{a}$ & 9 & $564^{a}$ & 50 \\
\hline $\mathrm{AL}$ & $199^{b}$ & 12 & $62^{b}$ & 3 & $24^{b}$ & 2 & $289^{b}$ & 15 & $1088^{b}$ & 110 \\
\hline $\mathrm{PC}$ & $107^{c}$ & 4 & $28^{a}$ & 1 & $52^{a}$ & 5 & $192^{c}$ & 5 & $302^{c}$ & 34 \\
\hline C & $77^{a}$ & 6 & $27^{a}$ & 2 & $20^{c}$ & 1 & $128^{a}$ & 7 & $264^{c}$ & 15 \\
\hline
\end{tabular}

${ }^{a-d}$ In any column, values with unlike superscript letters were significantly different $(P<0.05)$.

Initial body-weights did not differ between the four groups of animals with a combined mean value of 202 (SE $2, n$ 24) g. Final body-weights were highest in the WB and AL groups with respective means of 253 (SE 4) and 251 (SE 3) g. Body-weight was not significantly different in the PC group with a mean of 247 (SE 2) g but was significantly depressed in the C group at 239 (SE 4$) \mathrm{g}(P<0.01, \mathrm{C}$. WB, AL or C).

\section{Caecal mass, $p H$ and VFA concentrations}

The wet weight of caecal digesta was lowest in rats fed on the PC diet with a mean value of 2.09 (SE 0.24$) \mathrm{g}$. Caecal contents did not differ in weight between the WB and C groups with respective means of $3 \cdot 14$ (SE $0 \cdot 30$ ) and $2 \cdot 80$ (SE $0 \cdot 25) \mathrm{g}$, both of which were significantly $(P<0.01)$ increased over the PC diet. In the aleurone group, digesta wet weight rose to 5.05 (SE 0.26$) \mathrm{g}(P<0.001$, AL $v$. WB or $\mathrm{C})$. The mean $\mathrm{pH}$ of caecal digesta was lowest in the AL group, averaging 6.18 (SE 0.13), while the highest mean was recorded with the $\mathrm{C}$ diet, 7.51 (SE 0.04) $(P<0.001$, AL v. C). Caecal pH did not differ between the WB and PC diets with means of 7.28 (SE 0.06) and 7.07 (SE 0.16) respectively. Both values differed significantly $(P<0.05)$ from that found in the $\mathrm{C}$ or AL groups.

Concentrations of total caecal VFA were highest in rats given the AL diet and lowest in those consuming the cellulose-based ration where they were only $44 \%$ of those in the aleurone group (Table 3). In rats fed on the WB and PC diets total VFA were intermediate in concentration to the other two groups although the levels in the WB group were higher than those with the PC diet. Generally, changes in concentrations of the major individual VFA followed those in total VFA. Thus, in all groups acetate was the major VFA and was highest in the AL group and lowest with the $\mathrm{C}$ diet. However, in the AL group, while propionate was significantly increased above all other groups, the concentration of butyrate was unchanged from that with the $\mathrm{C}$ diet. In contrast, the concentration of butyrate was significantly raised in the groups of rats which had been given the $\mathrm{PC}$ and WB diets.

Calculation of the mass of caecal VFA altered some of these proportions (Table 3). For example, while total VFA remained lowest in the cellulose group, the total mass of VFA was unaffected by the PC diet but significantly raised in rats consuming WB. The mass of VFA was highest in digesta from the AL group of rats. It may also be calculated that the mass of propionate was highest in the AL group while that of butyrate was greatest in rats fed on the WB diet. 
Table 4. Concentrations ( $\mu \mathrm{mol} / \mathrm{ml}$ ) of total and individual plasma volatile fatty acids (VFA) in the hepatic portal vein of rats fed on diets containing wheat bran $(W B)$, aleurone $(A L)$, pericarp-seed coat $(P C)$ and cellulose $(C)$

(Mean values with their standard errors for six observations per group)

\begin{tabular}{|c|c|c|c|c|c|c|c|c|}
\hline \multirow[b]{2}{*}{ Diet } & \multicolumn{2}{|c|}{ Acetate } & \multicolumn{2}{|c|}{ Propionate } & \multicolumn{2}{|c|}{ Butyrate } & \multicolumn{2}{|c|}{ Total VFA } \\
\hline & Mean & $\mathrm{SE}$ & Mean & $\mathrm{SE}$ & Mean & $\mathrm{SE}$ & Mean & $\mathrm{SE}$ \\
\hline WB & $1 \cdot 16^{a}$ & 0.13 & $0 \cdot 23^{a}$ & 0.03 & $0 \cdot 29^{a}$ & $0 \cdot 04$ & $1.83^{a}$ & 0.17 \\
\hline $\mathrm{AL}$ & $2 \cdot 25^{b}$ & $0-15$ & $0.64^{b}$ & 0.05 & $0 \cdot 18^{b}$ & $0 \cdot 03$ & $3 \cdot 18^{b}$ & 0.21 \\
\hline $\mathrm{PC}$ & $1.05^{a}$ & 0.08 & $0 \cdot 22^{a}$ & 0.03 & $0 \cdot 23^{a, b}$ & 0.04 & $1 \cdot 66^{a}$ & $0 \cdot 10$ \\
\hline $\mathrm{C}$ & $0.73^{c}$ & 0.03 & $0 \cdot 16^{c}$ & 0.01 & $0 \cdot 1^{c}$ & 0.01 & $1 \cdot 09^{c}$ & 0.04 \\
\hline
\end{tabular}

$a_{c}^{a-c}$ In any column, values with unlike superscript letters were significantly different $(P<0.05)$.

\section{Plasma VFA}

Concentrations of hepatic portal venous VFA are shown in Table 4. As with levels in caecal digesta, total plasma short-chain fatty acids were highest in samples from rats given the AL diet and lowest with the $\mathrm{C}$ diet. Although the PC and WB groups did not differ from each other, they were significantly higher in VFA concentrations than the $\mathrm{C}$ group and lower than the AL group respectively. Acetate was the major hepatic portal venous VFA with all dietary treatments, contributing about $60-70 \%$ of the total and differences between groups in total VFA substantially mirrored changes in this acid. On the other hand, it was also noted that while propionate concentrations did not differ between the PC and WB diets, levels were raised threefold in the AL group. Butyrate was highest in hepatic portal venous plasma from animals consuming PC and WB diets and lowest in the C group of rats.

Acetate was the only VFA detectable in arterial plasma and concentrations were highest in the AL group, averaging $0.66(\mathrm{SE} 0.08) \mu \mathrm{mol} / \mathrm{ml}$. Plasma levels were significantly $(P<0.05)$ lower in the WB and C groups with similar means of 0.45 (SE $0.05, n 5)$ and 0.46 (SE 0.02$) \mu \mathrm{mol} / \mathrm{ml}$ respectively. Concentrations in the PC group did not differ significantly between any of the other treatments and averaged $0.53(\mathrm{SE} 0.03) \mu \mathrm{mol} / \mathrm{ml}$.

\section{Concentrations of blood glucose and liver glycogen}

No differences were noted in arterial blood glucose between any of the groups with mean values of 8.34 (SE 0.18), 8.26 (SE 0.33), 8.36 (SE 0.14) and $8.53($ SE 0.44$) \mu \mathrm{mol} / \mathrm{ml}$ for the C, WB, PC and AL groups respectively. Concentrations of liver glycogen were the same in rats fed on the C, WB and PC diets at 101 (SE 10), 112 (SE 5) and 97 (SE 6) $\mu$ mol glucose equivalents $/ \mathrm{g}$. Glycogen was significantly $(P<0.05)$ raised over the $\mathrm{PC}$ group in rats given $\operatorname{diet} \mathrm{AL}$ and averaged 121 (SE 8) $\mu \mathrm{mol}$ glucose equivalents $/ \mathrm{g}$.

\section{Plasma triacylglycerols and cholesterol}

Plasma triacylglycerols were lowest in rats consuming the AL diet and averaged 0.87 (SE 0.07$) \mu \mathrm{mol} / \mathrm{ml}$. Levels were significantly $(P<0.05)$ and equally higher with the three other treatments with means of: PC 1.15 (SE 0.13), C 1.07 (SE 0.06) and WB 1.25 (SE 0.16) $\mu \mathrm{mol} / \mathrm{ml}$. In contrast, total plasma cholesterol was highest in rats of the AL group at 3.98 (SE 0.19$) \mu \mathrm{mol} / \mathrm{ml}$. Levels were significantly $(P<0.05)$ lower $(\mu \mathrm{mol} / \mathrm{ml})$ in the PC (3.51 (SE 0.16)), WB (3.49 (SE 0.17)) and C (3.20 (SE 0.17)) groups, none of which differed from each other. 


\section{DISCUSSION}

Commercially available wheat bran is an aggregate of a number of cell types. The outer part consists of the virtually empty cells of the pericarp-seed coat tissue and the inner layer comprises the cells of the aleurone layer. The former have thick, lignified or cutinized cell walls whereas the aleurone layer cells are larger and have contents high in protein and lipid with cell walls that are thick but unlignified. The cell walls of the outer pericarp contain (mg/g) approximately 200 cellulose, 600 arabinoxylan and 120 lignin (Ring \& Selvendran, 1980) whereas aleurone cell walls contain 20 cellulose, 20 glucomannan, 650 arabinoxylan and $300(1 \rightarrow 3,1 \rightarrow 4)$ - $\beta$-glucan (Bacic \& Stone, $1981 a, b)$. The starchy endosperm walls in wheat contain approximately 40 cellulose, 70 glucomannan, 700 arabinoxylan and $200(1 \rightarrow 3,1 \rightarrow 4)$ - $\beta$-glucan (Mares \& Stone, 1973; Bacic \& Stone, 1981 b). The amount of this latter component associated with wheat bran depends on the milling regime but in the bran from 'high extraction' milling (such as used in the present study) it is low. The concentrations of VFA found in rats fed on the diets based on wheat bran and its components reflect these differences in composition. The highest concentrations of VFA in caecal contents were found in rats fed on the AL diet. These high values, together with the greatly elevated faecal mass of bacteria in that experimental group, are consistent with the high content of fermentable non-cellulosic polysaccharides in that fraction compared with the WB and PC diets. As expected, concentrations of VFA and the mass of bacteria in faeces were low in rats fed on $\alpha$-cellulose (diet $\mathrm{C}$ ), observations which accord with the fact that this polysaccharide is metabolized quite poorly by the large bowel microflora of the rat (Lang \& Briggs, 1976). However, the relations between dietary plant fibre and bacterial fermentation and its products are not entirely simple. For example, although the masses of faecal bacteria were similar to those in the cellulose group, caecal VFA concentrations were significantly higher in rats fed on diets containing wheat bran and pericarp-seed coat. These differences may reflect the presence of other factors in complex entities such as wheat bran and its fractionation products.

In keeping with previous observations (Storer et al. 1983, 1984; Topping et al. 1985 b), differences were also noted between the effects of fibre on the concentration and the mass of VFA in caecal digesta. For example, the $\mathrm{C}$ and $\mathrm{AL}$ diets respectively gave both the lowest and highest concentrations and mass of VFA in caecal digesta while the PC and WB diets gave intermediate concentrations of VFA but masses that differed considerably. The reasons for the divergence between mass and concentration is not known but may relate to the level of dietary fibre as well as its innate susceptibility to bacterial metabolism.

The mass of total caecal VFA in the PC group was low and did not differ from that obtained with the $\mathrm{C}$ diet. This relatively low yield of fermentation products with pericarp-seed coat accords with previous observations of the lower bacterial fermentation of otherwise susceptible polysaccharides found in lignified cell walls (Nyman \& Asp, 1982). Thus Stephen \& Cummings (1980) reported in experiments with humans that wheat bran enhanced faecal bulking through the passage of unaltered fibre. These authors also reported that other (fermentable) plant material raised faecal bulk through an increase in faecal bacteria. In the present experiment we found that the highest bacterial content was in faeces from rats fed on the AL diet and lowest with the PC diet. These findings, together with the results from the WB and C groups, are consistent with the levels of caecal VFA that were observed and also with the findings of Stephen \& Cummings (1980) in humans.

Although the AL diet gave the highest levels of total VFA, the increase was not uniform with all acids. Thus, in rats fed on the AL diet the mass of acetate and propionate rose by over $250 \%$ from the levels found in the $\mathrm{C}$ group but butyrate rose by only $120 \%$. In contrast the PC diet did not alter the caecal mass of the two former acids while that of 
butyrate equalled the AL group. Surprisingly, the greatest increase in the mass of butyrate occurred in the WB group. Several reasons may be put forward for these differences. Firstly, it was possible that they reflected variations in the amounts of dietary starch and sucrose that became adsorbed to different fibres and so escaped digestion and absorption in the small intestine. Studies in pigs (Topping et al. 1985a) have shown that VFA concentrations are raised by feeding milk and sucrose but that the increase depended upon the type of dietary fibre fed at the same time. Mono- and disaccharides appear to favour the generation of acetate (Remesy et al. 1980) whereas polysaccharides tend to yield relatively more propionate and butyrate on fermentation (Kim et al. 1978). Secondly, it is also feasible that the presence of pericarp and aleurone together in wheat bran was more effective in generating butyrate. We have shown recently that the fermentation of fibre mixtures (as opposed to single fractions) raise the relative concentration of this acid (Topping et al. $1985 b$ ). Finally, different diets may induce changes in the large bowel microflora (Smith \& Bryant, 1979) and, therefore, in the fermentation products.

The differences noted in the VFA profile could be significant metabolically if they occurred in man. It has been proposed that butyrate is a preferred substrate for the normal cells of the large bowel (Roediger, 1982) and that metabolism of the acid may also inhibit neoplastic transformations (Sakata \& Yajima, 1984). From that point of view the production of high VFA levels with the AL diet may not have been entirely advantageous as butyrate did not increase commensurately. On the other hand, caecal $\mathrm{pH}$ fell with increasing VFA mass and as the former variable has been related to colorectal carcinogenesis, it is possible that benefits of fermentation may still accrue with that of the AL type in spite of the bias away from butyrate as a product.

In confirmation of previous findings, concentrations of hepatic portal venous VFA were in proportion to the levels in the large bowel and the closest relation was with caecal VFA concentration but not mass. The concentrations of total VFA found with aleurone $(>3 \mu \mathrm{mol} / \mathrm{ml}$ ) were the highest by far that have been found in rats fed on purified diets containing dietary fibre at this level. It should be noted that the concentrations of hepatic portal venous VFA that were obtained with WB were rather higher than in a previous study (Illman et al. 1982). The difference may reflect the fact that in the present experiments wheat bran was present at $220 \mathrm{~g} / \mathrm{kg}$ diet (to give $100 \mathrm{~g}$ dietary fibre $/ \mathrm{kg}$ ) whereas in the earlier report wheat bran itself was added at $100 \mathrm{~g} / \mathrm{kg}$ diet but only gave $45 \mathrm{~g}$ dietary fibre $/ \mathrm{kg}$. Nevertheless it is clear that wheat bran is still a poorer generator of VFA than the aleurone fraction. Acetate was the only VFA found in arterial plasma and was present at levels considerably below those found in the hepatic portal vein, while other VFA were absent. These observations indicate net output of VFA by the gut and uptake by tissues such as liver and heart but differ from previous observations in the pig (Imoto \& Namioka, 1978). Our results support the suggestion that VFA make a significant contribution to metabolism although it has been proposed that VFA are metabolically inert (Hove \& King, 1979). The greater body-weight gain of rats consuming the AL, PC and WB diets compared with those fed on the $C$ diet also argues against this latter concept.

Levels of propionate in the hepatic portal vein of rats fed on AL were also extremely high in comparison with findings from previous studies (Illman et al. 1982; Storer et al. 1983, 1984). Anderson and colleagues have suggested that the beneficial effects of certain fibre preparations on blood glucose regulation and lowering of plasma cholesterol may relate to the generation of high levels of propionate (Chen et al. 1984). As in other experiments from this laboratory, no relation was found between individual VFA and either blood glucose or plasma lipids. Similarly, plasma triacylglycerols were unrelated to VFA while plasma cholesterol was raised with $\mathrm{AL}$, the diet which also gave the highest concentration of propionate. Of course, the distribution of lipoprotein cholesterol in the 
rat differs from that in man and so its elevation with the AL diet may be in high-density lipoproteins and not in other fractions. In any event, propionate and other VFA do not seem to mediate long-term changes in metabolism through acute variations in their concentration.

In conclusion it is clear that the effects of the two isolated wheat bran fractions on faecal bacterial mass and VFA concentrations were quite different from each other and the parent material. We conclude that the aleurone fraction is apparently a good substrate for large bowel fermentation and, in that regard, better than wheat bran and the isolated pericarp-seed coat. Obviously the fermentative properties of cereal brans are altered by production techniques and it is possible that wheat bran aleurone may be of nutritional value either in isolated form or as a constituent of wheat which has been processed to expose it to bacterial metabolism.

B.-Q.C. acknowledges the receipt of a WHO Fellowship and also the financial support of the City Council of Melbourne, Victoria and of CSIRO (Australia). B.A.S. thanks the Wheat Industry Research Council of Australia for support. The authors are grateful to $\mathrm{Mr}$ R. Hopkins (Water Wheel Flour Mills, Bridgewater, Victoria) for preparing the wheat bran, $\mathrm{Mr}$ J. Minfie for preparing the aleurone and pericarp-seed coat fractions, and $\mathrm{Dr}$ D. A. I. Suter (N. B. Love Industries, Sydney, New South Wales) for analyses of the fibre preparations used.

\section{REFERENCES}

Argenzio, R. A. \& Stevens, C. E. (1984). Proceedings of the Nutrition Society 43, 13-23.

Asp, N. G., Johansson, C. G., Halimer, H. \& Siljeström, M. (1983). Journal of Agricultural and Food Chemistry 31, $476-482$.

Association of Official Analytical Chemists (1984). Official Methods of Analysis, 14th ed. Methods 7.066-7.075. Arlington, Va, USA: AOAC.

Bacic, A. \& Stone, B. A. (1981a). Australian Joumal of Plant Physiology 8, 453-474.

Bacic, A. \& Stone, B. A. (1981 b). Australian Journal of Plant Physiology 8, 475-495.

Chen, W.-J. L., Anderson, J. W. \& Jennings, D. (1984). Proceedings of the Society for Experimental Biology and Medicine 175, 215-218.

Hove, E. L. \& King, S. (1979). Journal of Nutrition 109, 1274-1278.

Illman, R. J., Trimble, R. P., Snoswell, A. M. \& Topping, D. L. (1982). Nutrition Reports International 26, $439-446$.

Imoto, S. \& Namioka, S. (1978). Journal of Animal Science 47, 479-487.

Kim, K.-I., Benevenga, N. J. \& Grummer, R. H. (1978). Journal of Animal Science 46, 1648-1657.

Lang, J. A. \& Briggs, G. M. (1976). In Fiber in Human Nutrition, pp. 151-169 [G. A. Spiller and R. J. Amen, editors]. New York and London: Plenum Press.

Mares, D. J. \& Stone, B. A. (1973). Australian Journal of Biological Science 26, 793-812.

Nyman, M. \& Asp, N.-G. (1982). British Journal of Nutrition 47, 357-366.

Remesy, C., Demigne, C. \& Chartier, F. (1980). Reproduction, Nutrition et Developpement 20, 1339-1349.

Ring, S. G. \& Selvendran, R. R. (1980). Phytochemistry 19, 1723-1730.

Roediger, W. E. W. (1982). In Colon and Nutrition, pp. 11-24 [H. Kaspar and H. Goebell, editors]. Lancaster, Boston and The Hague: MTP Press.

Sakata, T. \& Yajima, T. (1984). Quarterly Journal of Experimental Physiology 69, 639-648.

Smith, C. J. \& Bryant, M. P. (1979). American Journal of Clinical Nutrition 32, 149-157.

Stephen, A. M. \& Cummings, J. H. (1980). Nature 281, 283-284.

Storer, G. B., Illman, R. J., Trimble, R. P., Snoswell, A. M. \& Topping, D. L. (1984). Nutrition Research 4, $701-707$.

Storer, G. B., Trimble, R. P., Illman, R. J., Snoswell, A. M. \& Topping, D. L. (1983). Nutrition Research 3 , 519-526.

Topping, D. L., Clark, D. G., Storer, G. B., Trimble, R. P. \& Illman, R. J. (1979). Biochemical Journal 184, $97-106$

Topping, D. L. \& Illman, R. J. (1986). Medical Journal of Australia 144, 307-309.

Topping, D. L., Illman, R. J., Taylor, M. N. \& McIntosh, G. H. (1985a). Annals of Nutrition and Metabolism 29, 325-331.

Topping, D. L., Illman, R. J. \& Trimble, R. P. (1985b). Nutrition Reports International 32, 809-814. 